\title{
Interaction Between Historical Earthquakes and the 2021 Mw7.4 Maduo Event and Their Impacts on the Seismic Gap Areas Along the East Kunlun Fault
}

\author{
Peiyu Dong ( $\square$ peiyuwork@163.com ) \\ Institute of Seismology China Earthquake Administration https://orcid.org/0000-0003-4604-3199 \\ Bin Zhao \\ Institute of Seismology China Earthquake Administration \\ Xuejun Qiao \\ Institute of Seismology China Earthquake Administration
}

Full paper

Keywords: Historical Earthquakes, Maduo Event, Seismic Gap Areas

Posted Date: October 12th, 2021

DOI: https://doi.org/10.21203/rs.3.rs-934288/v1

License: (c) (1) This work is licensed under a Creative Commons Attribution 4.0 International License. Read Full License

Version of Record: A version of this preprint was published at Earth, Planets and Space on March 18th, 2022. See the published version at https://doi.org/10.1186/s40623-022-01589-3. 


\section{Abstract}

On May 21, 2021 (UTC time), a Mw7.4 earthquake struck Maduo County, Qinghai Province, China. The rupture of this typical strike-slip event and its aftershocks along the Kunlun-Jiangcuo fault (JCF) propagated approximately $170 \mathrm{~km}$ from the epicenter. In this study, we calculated the coseismic and postseismic Coulomb stress changes induced by 14 historical earthquakes and investigated their impacts on the 2021 Maduo source area. We found that the JCF is in the stress shadow of these historical events with a combined $\triangle$ CFS range of approximately -0.4 to $-0.2 \mathrm{MPa}$. Since the seismogenic fault of the 1937 event is nearly parallel and close to the JCF, the rupture of the 1937 event had the greatest inhibitory effect on Maduo source area. We hypothesize that the actual loading rate at the depth of the seismogenic layer in the Maduo source area is much higher than the simulated value $(0.3 \mathrm{kPa} / \mathrm{a})$. Consequently, the Maduo earthquake still occurred despite the considerable delaying effect of these historical earthquakes (especially the 1937 event). Our findings also indicate that the tectonic stress in the eastern Bayanhar block is still rapidly accumulating and adjusting. Our investigation further reveals the enhanced stress induced by the historical and Maduo events with $\triangle \mathrm{CFS}$ values of approximately $30 \sim 300 \mathrm{kPa}$ and $50 \sim 300 \mathrm{kPa}$ on the XDS and the eastern end of the EKF, respectively, not only on the MMS but also at the eastern end of each branch segment of the EKF. Hence, considering the accumulation of tectonic stress, we suggest that the seismic hazard in these two regions has been promoted.

\section{Introduction}

On May 21, 2021 (UTC time), a Mw 7.4 earthquake struck Maduo County, Qinghai Province, China, with the hypocenter located at approximately $\left(98.25^{\circ} \mathrm{E}, 34.59^{\circ} \mathrm{N}\right.$ ) and a focal depth of $10.0 \mathrm{~km}$ (USGS, Fig. 1). The focal mechanism solution (strike $=285^{\circ}$, dip $=85^{\circ}$, rake $=0^{\circ}$ ) and slip distribution model suggest that this earthquake was a typical strike-slip event. The total rupture of this event and its aftershocks along the Kunlun-Jiangcuo fault (JCF) propagated eastward and westward approximately $170 \mathrm{~km}$ from the epicenter (Wang et al., 2021).

The JCF, which is a branch fault of the East Kunlun Fault (EKF), is located in the eastern-central area of the Bayanhar block. Before the 2021 Maduo earthquake occurred, no large earthquakes had been documented along the JCF. However, the seismicity in the surrounding area has been extremely active as of late: the western part of the EKF experienced the massive 2001 Kokoxili Ms8.1 earthquake, and the eastern margin of the Bayanhar block suffered the destructive 2008 Ms8.0 Wenchuan, 2013 Ms7.0 Lushan, and 2017 Jiuzhaigou Ms7.0 earthquakes. In addition, the Xidatan-Dongdatan segment (XDS, 93 ${ }^{\circ}$ $~ 95.5^{\circ} \mathrm{E}$, Fig. 1) and Maqin-Maqu segment (MMS) of the EKF were thought to be seismic gap zones due to the lack of historical earthquake records for at least 300 years, especially the MMS, which is highly populated (Wen et al., 2007, 2018; Xu et al., 2014; Li et al., 2011a; Shan et al., 2015; Li et al., 2017; Zhu et al., 2020; Pan et al., 2021). Geodesic research further suggests that multiple segments along the eastern section of the EKF, especially the MMS, are locked with a store of accumulated elastic strain energy, indicating the possible occurrence of strong earthquakes (Li et al., 2019; Zhu et al., 2020; Zhu et al., 2021a). However, the 2021 Maduo earthquake, another strong event that occurred along the eastern section of the EKF after the 2017 M7.0 Jiuzhaigou earthquake, did not occur in the seismic gap of the main fault but on the branch fault to the south of the EKF. This seismic activity indicates that the eastern margin of the Bayanhar block, especially the eastern section of the EKF, is still in the stress adjustment stage. After the 2021 event, the value of estimating the seismic hazards within the seismic gaps has become increasingly significant for this region.

The occurrence of earthquakes is controlled predominantly by the regional tectonic stress field, however, comprehensive absolute stress data in the surrounding area of the rupture zone remain unknown. Nevertheless, we can calculate the stress perturbation to evaluate the seismic hazard. Many studies over the last few decades have suggested that a small stress loading can trigger large earthquakes if the fault system is sufficiently close to failure. Hence, calculating the Coulomb failure stress change ( $\triangle \mathrm{CFS})$ prompted by a major shock can identify faults at an increased risk of triggering earthquakes and indicate future seismic activity (Stein and Lisowski, 1983; Harris, 1998; Parsons et al., 2008; Xiong et al., 2010). A stress change of $10 \mathrm{kPa}$ is usually considered the threshold for triggering an earthquake (King et al., 1994; Stein, 1999). By using this theoretical method, numerous previous studies have analyzed the aftershocks triggered by main shocks (King et al., 1994; Stein, 1999; Toda et al., 2008; Liu et al., 2017) and the interactions between large earthquakes (Stein, 1994; Shan et al., 2015; Liu et al., 2018; Jia et al., 2018).

How did historical earthquakes impact the 2021 Maduo earthquake? More importantly, did the 2021 Maduo earthquake change the stress conditions on the active faults around the rupture zone and thus impact the seismic hazard along the eastern segment of the EKF? To investigate these questions, in this study, we simulated the stress perturbation induced by historical events on and around the JCF and the $\triangle C F S$ on the other active faults surrounding the JCF. Based on these results, we identified these faults as either close to or far from Coulomb failure. We also examined the sensitivities of the results to the various parameters of receiver fault and source slip models. 
Table 1

Information of the 14 historical earthquakes

\begin{tabular}{|c|c|c|c|c|c|c|c|c|c|c|c|}
\hline \multirow[t]{2}{*}{ No. } & \multirow[t]{2}{*}{ Date } & \multirow[t]{2}{*}{ Magnitude } & \multicolumn{2}{|c|}{ Epicenter } & \multirow[t]{2}{*}{ Strike/ } & \multirow[t]{2}{*}{ Dip/ } & \multirow[t]{2}{*}{ Rake/ } & \multirow[t]{2}{*}{ Length/Km } & \multirow[t]{2}{*}{ Width/Km } & \multirow[t]{2}{*}{ Slip/m } & \multirow[t]{2}{*}{ Reference } \\
\hline & & & Lat ${ }^{\circ}$ & Long/ ${ }^{\circ}$ & & & & & & & \\
\hline \multirow[t]{2}{*}{1} & 01/08/1879 & 8 & 33.2 & 104.7 & 70 & 70 & -34 & 190 & 25 & 7.2 & $\begin{array}{l}\text { Wells and } \\
\text { Coppersmith } \\
\text { 1994; }\end{array}$ \\
\hline & & & & & & & & & & & $\begin{array}{l}\text { Hou et al, } \\
2005 ; \text { Shan } \\
\text { et al, } 2015\end{array}$ \\
\hline 2 & $16 / 12 / 1920$ & 8.5 & 36.62 & 105.4 & 115 & 90 & 0 & 220 & 25 & 8.0 & $\begin{array}{l}\text { Xiao and he, } \\
2015\end{array}$ \\
\hline 3 & $25 / 08 / 1933$ & 7.8 & 31.9 & 103.4 & 165 & 60 & 28 & 100 & 23 & 2.69 & $\begin{array}{l}\text { Wang and } \\
\text { Shen, } 2011\end{array}$ \\
\hline \multirow[t]{2}{*}{4} & 07/01/1937 & M7.6 & 35.4 & 97.69 & 110 & 70 & 15 & 138 & 20 & 3.31 & $\begin{array}{l}\text { Peter Molnar } \\
\text { and } \\
\text { Deng,1984 }\end{array}$ \\
\hline & & & & & & & & & & & $\begin{array}{l}\text { Shen et } \\
\text { al,2003 }\end{array}$ \\
\hline 5 & $17 / 03 / 1947$ & M7.6 & 33.3 & 99.5 & 135 & 90 & 0 & 139 & 20 & 3.31 & $\begin{array}{l}\text { Shen et } \\
\text { al,2003; Liu } \\
\text { et al. 2021; } \\
\text { Wan et al., } \\
2007\end{array}$ \\
\hline 6 & $19 / 01 / 1963$ & 7.1 & 35.5 & 96.44 & 277 & 80 & -10 & 68 & 14 & 1.17 & $\begin{array}{l}\text { Wells and } \\
\text { Coppersmith } \\
1994 ; \text { Wan } \\
\text { et al,2007 }\end{array}$ \\
\hline 7 & 16/08/1976 & 7.2 & 32.72 & 104.08 & 165 & 63 & 40 & 30 & 12 & 1.09 & $\begin{array}{l}\text { Jones et } \\
\text { al.,1984 }\end{array}$ \\
\hline 8 & 23/08/1976 & 7.2 & 32.48 & 104.1 & 165 & 65 & 40 & 30 & 12 & 1.09 & $\begin{array}{l}\text { Jones et } \\
\text { al.,1984 }\end{array}$ \\
\hline 9 & $26 / 04 / 1990$ & 7.0 & 36.06 & 100.33 & 346 & 78 & 128 & 59 & 13 & 0.95 & $\begin{array}{l}\text { Wan et } \\
\text { al,2007 }\end{array}$ \\
\hline 10 & $12 / 09 / 2000$ & Ms6.6 & 35.5 & 99.5 & 343 & 80 & -170 & 33 & 10 & 0.42 & $\begin{array}{l}\text { Wells and } \\
\text { Coppersmith } \\
\text { 1994; }\end{array}$ \\
\hline 11 & $14 / 11 / 2001$ & Mw7.8 & 35.92 & 90.54 & 99 & 90 & 5 & - & - & - & $\begin{array}{l}\text { Lasserre et } \\
\text { al,2005 }\end{array}$ \\
\hline 12 & $12 / 05 / 2008$ & Ms8.1 & 31.0 & 103.4 & 229 & 32 & 118 & - & - & - & $\begin{array}{l}\text { Wang et al, } \\
2011\end{array}$ \\
\hline 13 & $10 / 04 / 2010$ & Ms7.1 & 33.2 & 96.9 & 165 & 60 & 28 & - & - & - & Li et al, 2011 \\
\hline 14 & 08/08/2017 & Ms7.0 & 33.2 & 103.9 & 151 & 83 & 0 & - & - & - & $\begin{array}{l}\text { Liu et al, } \\
2019\end{array}$ \\
\hline
\end{tabular}

\section{Tectonic Setting And Historical Earthquakes}

The Bayanhar block, one of the important tectonic units involved in the eastward extrusion of the Tibetan Plateau, is accelerating toward the east-southeast. The EKF, which is characterized by high-velocity sinistral strike-slip motion, constitutes the northern margin of this block and extends approximately $2000 \mathrm{~km}$ with an average strike of $270^{\circ} \sim 290^{\circ}$ (Xu et al., 2002; Deng et al., 2014; Wen et al., 2018). Its slip rate gradually decreases from west to east, with the horizontal slip component being absorbed by the eastern margin thrust structure (the Longmen Shan fault zone, LSF) (Kirby et al., 2007; Li et al., 2011).

Consequently, many strike-slip earthquakes have occurred on and around the EKF, such as the 1937 M7.6 earthquake that occurred on the Tuosuo Lake segment (TLS), the 1947 M7.6 earthquake that occurred on the Dari fault (DF) to the south of the EKF, and the 2001 M8.1 
Kokoxili earthquake that occurred on the western Kusai Lake segment, which was the largest earthquake recorded along the EKF in recent decades with a surface rupture spanning $426 \mathrm{~km}$ (Xu et al., 2002). In contrast, primarily thrust and slip-strike earthquakes have occurred on and around the eastern margin of the Bayanhar block, including the 1879 M8.0 Wudu event, 1933 M7.8 Diexi event, 1976 Ms7.2 Songpan event, 2008 Ms8.0 Wenchuan event, 2013 Ms7.0 Lushan event and 2017 Ms7.0 Jiuzhaigou event. In addition, the 2010 Ms7.1 Yushu earthquake occurred on the Ganzi-Yushu fault zone, which represents the southern margin of the Bayanhar block.

Several historical earthquakes have also been recorded to the north of the eastern segment of the EKF, such as the M7.0 and M6.6 events that struck in 1990 and 2000, respectively. However, these earthquakes were neglected by previous studies that modeled earthquake stress changes (Xiong et al., 2010; Shan et al., 2015; Li et al., 2021). Thus, this study quantified the contributions of these events to the $\Delta$ CFS on the EKF and other regions. Furthermore, although the 1920 M8.5 Haiyuan event did not occur on or around this block, probably had a certain impact on the study area due to its considerable magnitude, and hence, this event was also included in our study. However, the 2013 Lushan earthquake had a weak stress impact on the eastern segment of the EKF (ref) and was excluded.

The source parameters, such as the epicenter location and focal mechanism solution, can be determined from previous studies and earthquake records. However, due to the scarcity of information, the slip distributions of historical earthquakes and less studied events (such as the 1879, 1920, 1933, 1937, 1947, 1963, 1976, 1990 and 2000 earthquakes) can be estimated only by the empirical formula of Wells and Coppersmith (1994). In contrast, the detailed rupture parameters and slip distribution models for other recent events (such as the 2001, 2008, 2010 and 2017 earthquakes) have usually been inverted through seismic and geodesy data (Lassere et al., 2005; Wang et al., 2011; Li et al., 2011b; Liu et al., 2019). Fourteen historical events are included in this study, and the details are shown in Fig. 1 and Table 1.

\section{Method And Models}

From the Coulomb friction criterion (Harris, 1998), the $\triangle$ CFS on a fault interface is defined as

$\Delta \mathrm{CFS}=\Delta \tau+\mu^{\prime} \times \Delta \sigma_{\mathrm{n}}(1)$

where $\Delta \tau$ is the shear stress change on the receiver fault interface (positive along the inferred slip direction), $\Delta \sigma_{n}$ is the normal stress change (positive for fault unclamping), and $\mu^{\prime}$ is the equivalent friction coefficient ( $0 \sim 1.0$ ), reflecting the weight relationship between $\Delta \tau$ and $\Delta \sigma_{n}$ in the value of $\Delta$ CFS. If $\Delta \tau$ and $\Delta \sigma_{n}$ having opposite polarities, the polarity of $\Delta$ CFS depends on the value of $\mu$ '. This equation means that faults with increases in both shear stress and normal stress have a positive $\triangle C F S$ and thus are closer to failure. In contrast, faults with a negative $\triangle$ CFS are relatively far away from failure, which also means they are in the stress shadow (Harris, 1998).

To calculate the $\triangle$ CFS induced by the rupture of earthquakes, it is necessary to calculate not only the coseismic stress release effects but also the viscous relaxation of the flexible middle and lower crust, which has a long-term stress adjustment effect on the upper elastic crust. According to previous seismic studies (Meissner et al., 2004; Silver, 2008; Shan et al., 2015; Jia et al., 2017), a four-layer crustal model is built, and the parameters (thickness, density and coefficient of viscosity of each layer) of the layered model can be found in Table 2 .

We use the PSGRN/PSCMP software package (Wang et al., 2006) to calculate the stress changes and project them onto different receiver faults to calculate $\triangle \mathrm{CFS}$. Generally, the expected slip direction and geometric parameters of receiver faults are difficult to be constrained clearly. However, we can estimate these parameters through the earthquake focal mechanism solutions of historical earthquakes that occurred on or near those faults.

Table 2

Crustal model

\begin{tabular}{|llllll|}
\hline Layer & Depth $(\mathrm{km})$ & $\mathbf{V p}(\mathrm{km} / \mathbf{s})$ & $\mathbf{V s}(\mathrm{km} / \mathbf{s})$ & $\boldsymbol{\rho}\left(\mathrm{kg} / \mathrm{m}^{3}\right)$ & $\mathbf{H}(\mathrm{Pa} \cdot \mathbf{s})$ \\
\hline 1 & 20 & 6.0 & 3.52 & 2750 & - \\
\hline 2 & 40 & 6.3 & 3.68 & 2800 & $1.0 \mathrm{e} 20$ \\
\hline 3 & 50 & 6.8 & 3.82 & 3100 & $1.0 \mathrm{e} 18$ \\
4 & 100 & 8.0 & 4.60 & 3350 & $2.0 \mathrm{e} 20$ \\
\hline
\end{tabular}

\section{Results}

\subsection{The stress imparted to the hypocenter of the 2021 Maduo earthquake}


To investigate the relationships between the 14 historical earthquakes and the 2021 Maduo event, we calculated the coseismic and postseismic stress changes at the hypocenter $\left(98.34^{\circ} \mathrm{E}, 34.59^{\circ} \mathrm{N}\right.$, depth of $\left.10 \mathrm{~km}\right)$ of the Maduo earthquake caused by those 14 events. Since the rupture direction of this event was approximately E-W, the E-W $(\mathrm{x})$ and N-S (y) stress components probably had the greatest contributions to the $\Delta$ CFS. Fig. 2 visualizes the values of $\Delta S x x, \Delta$ Syy and $\Delta S x y$ in detail. The 1937 M7.6 earthquake (No. 4) reduced the greatest impact with $\Delta S x x, \Delta S y y$, and $\Delta S x y$ values of $-60 \mathrm{kPa},-280 \mathrm{kPa}$, and $-45 \mathrm{kPa}$, respectively. The $1947 \mathrm{M} 7.6$ earthquake (No. 5) produced combined stress changes ( $\Delta S x x, \Delta S y y, \Delta S x y$ ) of $-106 \mathrm{kPa}, 27 \mathrm{kPa}$, and $-72 \mathrm{kPa}$, respectively. As shown in Fig. 1, not only the epicenters of the 1937 and 1947 events were close to the Maduo earthquake but also the magnitude is considerable great. While the magnitudes of the 1879 (No. 1), 1920 (No. 2), 1933 (No. 3), 2001 (No. 11) and 2008 (No. 12) earthquakes were greater than 7.8, they were far from the source area of the 2021 event, so these events had relatively small impacts. The impacts induced by other events (No. 7, No. 8, No. 9, No. 10 , No. 13 and No. 14) were negligible due to their smaller magnitude $(M<=7.0)$ or relatively long distance (more than $500 \mathrm{~km})$ from the target area, as shown in Fig. 1. Theoretical calculations indicate that the attenuation of elastic static stress is inversely proportional to the cubed distance from the seismic source zone, and the value of the long-distance stress change may be lower than the tidal stress level (Hill et al., 1993). Therefore, the impact of a large, distant earthquake on the Maduo area should be less than that of a nearby event with a relatively small magnitude.

\subsection{The stress changes caused by the 1937 and 1947 earthquakes}

The 1937 (No. 4) and 1947 (No. 5) events, both of which were sinistral strike-slip events, generated considerable stress changes near the JCF, as shown in Fig. 3. The 1937 event exhibited compressional deformation in the N-S and E-W directions, whereas the 1947 event resulted in slight tensile deformation in the E-W direction along the JCF. The JCF is located in the middle of the rupture zone of these two events and thus suffered west-to-east compression during the 1937 event and nearly east-to-west (that is, in the opposite direction) compression during the 1947 event.

The strike-slip fault interaction process is demonstrated in the sketch map of Fig. 4 by showing the relationship between the interseismic crustal displacement due to tectonic loading and earthquake-induced crustal deformation. However, the Bayanhar block is moving from west to east, and the southern side of the JCF (the interior of the block) moves faster than the northern side. Consequently, the JCF is characterized by sinistral strike-slip motion, as shown by the red arrow in Fig. 4. The 1937 event accelerated the movement to the north of the JCF, while the 1947 event suppressed the movement to the south of the JCF, both effects were contrary to the tectonic movement of the JCF. Therefore, the occurrence of these two events, especially the 1937 event, yielded a $\triangle$ CFS value of $-235 \mathrm{kPa}$ and thus delayed the occurrence of the 2021 Maduo earthquake (Fig. 5). This finding is supported by the results of previous studies that interpreted the interactions of parallel strike-slip fault systems: when slip takes place on a model fault, the shear stress on other parallel faults is reduced, inhibiting the occurrence of another earthquake around the seismogenic fault (Kato and Lei, 2001; Chen et al., 2008).

(a) (c) are the $\Delta S x x, \Delta$ Syy, $\Delta$ Sxy caused by 1937 earthquake, respectively; (d) (f) are the $\Delta S x x, \Delta$ Syy, $\Delta$ Sxy caused by 1947 earthquake, respectively; Black beach ball show the Maduo earthquake, black circles represent the aftershock of Maduo event, black stars define the epicenter of the earthquakes.

\subsection{The total $\triangle$ CFS prior to 2021}

We calculated the $\triangle$ CFS at the hypocenter of the Maduo event caused by each historical event. Since the focal depths of the 2021 event given by different research institutions are inconsistent, we calculated the $\triangle$ CFS at two depths: $10 \mathrm{~km}$ and $15 \mathrm{~km}$. Then, the stress changes produced by the 14 historical events were projected to the receiver fault interface (strike $=285^{\circ}$, dip $=85^{\circ}$, slip $=0^{\circ}$, same as the mechanism of the Maduo event) while assuming an effective friction coefficient of $\mu^{\prime}=0.4$. The result is shown in Fig. 5 . Although the values vary at different depths, the polarity is the same, and the difference is small. The $\triangle \mathrm{CFS}$ exhibited a maximum decrease of approximately $-235 \mathrm{kPa}$ and $-241 \mathrm{kPa}$ due to the 1937 event at depths of $10 \mathrm{~km}$ and $15 \mathrm{~km}$, respectively. The corresponding values caused by events No. 2 and 5 were in the approximate range of -15 to $-25 \mathrm{kPa}$, while other events (Nos. 3, 6, 10,11, 12, and 13) increased the $\Delta \mathrm{CFS}$ by only $1 \sim 4 \mathrm{kPa}$. Generally, a negative $\triangle$ CFS results in a decrease in seismic activity in the stress shadow (unloaded stress regions).

Figure 5 The coseismic and postseismic $\Delta$ CFS at the epicenter of 2021 Maduo earthquake induced by historical earthquakes, at different depth $10 \mathrm{~km}$ and $15 \mathrm{~km}$.

\subsection{Coulomb stress transfer on the major faults after 2021}

Figure 7 provides details of the cumulative $\triangle$ CFS at a depth of $10 \mathrm{~km}$ along the major active faults in the target area just after the 2021 Maduo earthquake occurred. The parameters of each major fault are shown in Table 3 with a coefficient frictional parameter $\mu^{\prime}$ of 0.4. The 
$\triangle$ CFS was positive over most of the major faults, such as the eastern and western segments of the branch faults of the EKF (A1, A2, B1, B2, B3, and B4 in Figure 7), and the western segment of the DF exhibited an increase of approximately 0.2 0.3 MPa. Regions A and B in Figure 7 represent typical apparent seismic gaps, especially segment B1, which is the MMS of the EKF. This seismic gap has been tectonically quiet with no large earthquake having been recorded for over 300 years. Generally, an enhanced $\Delta C F S$ corresponds to increased seismic risk.

Figure $9 \Delta$ CFS on $A 1$ and $B 1$ at time intervals of $0,10,50$ and 100 years after 2021

Table 3

Geometric parameters of each fault

\begin{tabular}{|lllllllllllll|}
\hline & F1-1 & F1-2 & F1-3 & F1-4 & F1-5 & F2 & F3 & F4 & F5 & F6 & F7 & F8 \\
\hline Strike angle $^{\circ}$ & 270 & 290 & 315 & 325 & 290 & 325 & 315 & 325 & 335 & 280 & 345 & 345 \\
\hline Dip angle $^{\circ}$ & 85 & 85 & 85 & 85 & 85 & 85 & 85 & 85 & 85 & 85 & 60 & 60 \\
\hline Rake angle $^{\circ}$ & 0 & 0 & 0 & 0 & 0 & 0 & 0 & 0 & 0 & 0 & 180 & 45 \\
\hline
\end{tabular}

\section{Discussion And Conclusion}

\subsection{Effect of the slip model}

The value of $\triangle$ CFS depends on various parameters, such as the slip model of the earthquake, the effective friction coefficient $\mu^{\prime}$, the dip angle, the slip angle and the rake angle. First, we investigated the sensitivity of the stress to the slip model. Previous studies have suggested that the stress change in the near field is probably impacted by different slip models, but there is no obvious difference in the far field (Qu et al., 2016; Liu et al., 2020). After the 2017 Ms7.0 Jiuzhaigou earthquake occurred, many scholars discussed whether the 2017 event was triggered by the 2008 Wenchuan earthquake (Jia et al., 2018; Huang et al., 2019). Our previous study suggested that the difference in the chosen source slip model for the 2008 earthquake is the main reason for this controversy (Dong et al., 2019).

Due to the scarcity of data, it is difficult to accurately determine the slip models for the 14 historical earthquakes selected in this paper, especially the older events. For example, for the 1933 M7.8 Diexi earthquake (event No. 3), different scholars have reported different focal mechanism solutions: sinistral strike-slip (Wang and Shen, 2011), dextral strike-slip (Chen et al., 1994), and tensile rupture (Ren et al., 2018). However, the location of this earthquake is far from the rupture zone of the Maduo event, and the impact on the hypocenter of the 2021 earthquake was less than $10 \mathrm{kPa}$ (Fig. 2). Hence, it is not necessary to discuss the impact induced by this event.

However, the 1947 M7.6 Dari earthquake (event No. 5) had a certain impact on the calculated stress change. Previous studies reported two different mechanisms: the first mechanism involved a strike of $135^{\circ}$, dip of $90^{\circ}$, and slip angle of $0^{\circ}$, representing a typical sinistral strikeslip fracture model (Shen et al., 2003; Liu et al., 2021); the second mechanism involved a strike of $135^{\circ}$, dip of $60^{\circ}$, and slip angle of $60^{\circ}$ (Molnar and Deng, 1984; Shan et al., 2015). In this study, we adopted the first mechanism, but it is still necessary to discuss the influence of the second rupture mechanism. Fig. 10 shows the distributions of the stress perturbation components $\Delta S x x, \Delta S y y$, and $\Delta S x y$ under the second mechanism, the values of which at the epicenter of the Maduo earthquake are $-83.5 \mathrm{kPa},-43.2 \mathrm{kPa}$, and $-33.2 \mathrm{kPa}$, respectively. The corresponding results under the first mechanism are $-106 \mathrm{kPa}, 27.3 \mathrm{kPa}$, and $-71.9 \mathrm{kPa}$ (Fig. 2), which are evidently different from the former, especially the polarity of $\Delta$ Syy. Accordingly, we calculated $\Delta$ CFS values (strike $\left.=285^{\circ}, \mathrm{dip}=85^{\circ}, \mathrm{rake}=0^{\circ}, \mu^{\prime}=0.4\right)$ of $-7.5 \mathrm{kPa}$ and -30 $\mathrm{kPa}$ under the first and second mechanisms, respectively. Although the results are different, the overall impact on the conclusion of this study is limited.

\subsection{Sensitivity to variations in the parameters of the receiver fault}

To evaluate the sensitivity of the calculated stress change to difference in the parameters of the receiver fault, we changed one parameter in each case while keeping the remaining parameters constant. Here, the MMS (B1 segment in Fig. 7) is taken as an example. Fig. 11 indicates that the $\triangle \mathrm{CFS}$ varies with differences in the chosen parameters. The results based on the different strike angles, dip angles and rake angles are shown in Fig. 11(a), (b) and (c), respectively. Fig. 11(a) suggests that the larger the strike angle is, the smaller the $\triangle$ CFS, and the value even changes from positive to negative at the eastern end. Fig. 11(b) and (c) show that the $\triangle C F S$ is less sensitive to variations in the dip angle and rake angle. It should be noted that this conclusion can probably be satisfied only under the conditions in this study. 
Figure 11(d) shows the impact caused by the equivalent friction coefficient $\mu$, indicating that the $\Delta$ CFS increases with an increase in the friction coefficient. However, a fault with a higher friction coefficient is less likely to rupture. The reason for this contradiction is that the shear stress change $(\Delta \tau)$ is negative, and the normal stress change $\left(\Delta \sigma_{n}\right)$ is positive. According to formula (1), the larger $\mu$ ' is, the greater the weight of $\Delta \sigma_{n}$ in the computation of $\Delta$ CFS. Therefore, $\Delta$ CFS increases as $\mu^{\prime}$ increases, as has been shown in previous studies (Toda et al., 2011; Parsons et al., 1999). Zhu and Miao (2016) discussed this problem and suggested that the tectonic background stress should be considered when calculating the variation in the $\triangle$ CFS caused by changes in $\mu^{\prime}$. Therefore, the selection of $\mu^{\prime}$ is important in the $\Delta$ CFS calculation without considering the tectonic stress field.

\subsection{Interseismic stress loading rate}

Based on the generalized Hooke's law, Shan et al. (2015) evaluated that the tectonic Coulomb stress loading rate is approximately $2 \sim 3$ $\mathrm{kPa} / \mathrm{a}$ on the TLS and $0.2 \sim 0.5 \mathrm{kPa} / \mathrm{a}$ on the MMS based on the fault slip rate (11.2 4.9 mm/a). Generally, by assuming an elastic modulus of $3 \mathrm{GPa}$, a slip rate of $1 \mathrm{~mm} /$ a corresponds roughly to a loading rate of $0.3 \mathrm{kPa} / \mathrm{a}$. Zhu et al. (2021) determined the slip rate on the JCF to be $1.2 \pm 0.8(0.4 \sim 2.0) \mathrm{mm} / \mathrm{a}$ based on interseismic GPS observations across the Maduo region. We estimated the rate of stress accumulation on the JCF to be approximately $0.1 \sim 0.6 \mathrm{kPa} / \mathrm{a}$. Liu et al. (2021) used the numerical finite element method with average GPS velocity data from 1991 to 2015 to simulate the regional interseismic loading rate and computed the value on the DF of $0.21 \mathrm{kPa} / \mathrm{a}$. The JCF is spatially close to the DF, and they are both characterized by left-lateral strike-slip motion, so we assume that their fault slip rates and stress accumulation rates are roughly equivalent and within the range of the estimated value $(0.1 \sim 0.6 \mathrm{kPa} / \mathrm{a})$.

Based on the estimated loading rate, the stress released by the 14 historical earthquakes (200 300 kPa) is equivalent to $300 \sim 1000$ years of an interseismic stress accumulation. However, the Maduo earthquake was delayed primarily by (and occurred less than 100 years after) the 1937 event. On the one hand, the interseismic tectonic loading rate we estimated or modeled may be lower than the actual rate. Zhan et al. (2021) suggested that there are generally deep and undulating high-conductivity layers in the middle and lower crust within the Bayanhar block (that is, mechanically weak layers that easily deform) based on magnetotelluric profiles across the Maduo seismic source area. The source areas of the 2021 Maduo and 1947 Dari events are located at the junction of high-conductivity and high-resistivity bodies. Stress would migrate to the highly resistant brittle upper crust, causing stress to concentrate locally. These two events may have been controlled by the shear and shortening of these high-conductivity layers. Therefore, we hypothesize that the actual deep tectonic loading rate is much larger than the estimated value based on surface geodynamic data. On the other hand, previous studies suggested that seismic vibrations can change the mechanical strength of rock bodies and faults, thereby modifying the hydrological characteristics of rocks and sediments (Taira et al., 2009; Moyer et al., 2018; Shi et al., 2021). As a result, the rupture conditions become more sensitive, the stress re-accumulates to a lower value, and rupture may occur. Therefore, we hypothesize that the actual deep fault loading rate is larger than the estimated value based on surface geodesy data and that the seismogenic conditions of the JCF may be suppressed. Consequently, the Maduo earthquake occurred despite the considerable delaying effects of the 14 historical earthquakes (especially the 1937 event). This finding further indicates that the tectonic stress in the eastern Bayanhar block is still rapidly accumulating and adjusting.

\subsection{Seismic hazards of seismic gaps A and B after 2021}

Based on geomorphological research, Van der Woerd et al. (2002) suggested that the average long-term slip rate of the EKF was approximately $11.7 \pm 1.5 \mathrm{~mm} / \mathrm{a}\left(94^{\circ} \mathrm{E}\right), 10 \mathrm{~mm} / \mathrm{a}\left(99^{\circ} \mathrm{E}\right)$, and $12.5 \pm 2.5 \mathrm{~mm} / \mathrm{a}\left(100^{\circ} \mathrm{E}\right)$. More recent geodesy data indicate that the slip rate decreases gradually from west to east, with a rate of $10 \mathrm{~mm} / \mathrm{a}$ on the TLS that decays to 1 5 mm/a (Kirby et al., 2007; Lin and Guo, 2008; Li et al., 2019; Diao et al., 2019; Zhu et al., 2021) on the MMS. We estimate that the loading rates of the XDS-ALS, TLS, and MMS are approximately $3 \mathrm{kPa} / \mathrm{a}, 2.7 \sim 1.5 \mathrm{kPa} / \mathrm{a}$, and 1.5 0.3 kPa/a, respectively. However, the simulated results (Liu et al., 2021) show that the corresponding values are $0.29 \mathrm{kPa} / \mathrm{a}, 0.19 \mathrm{kPa}$, and $0.16 \mathrm{kPa} / \mathrm{a}$, the first two of which (corresponding to the XDS-ALS and TLS, respectively) are roughly ten times smaller than the estimated values above.

As mentioned above, due to local anomalies within the crust, the simulated results (Liu et al., 2021) and estimated values are inconsistent, which may also be lower than the actual tectonic loading rates. Only under the calculations in this study do all 14 historical earthquakes and the Maduo event yield a total $\triangle \mathrm{CFS}$ of $30 \sim 300 \mathrm{kPa}$ in the gap A region. Given an interseismic tectonic loading rate of $3 \mathrm{kPa} / \mathrm{a}$, the promoted stress is equivalent to tectonic loading for approximately $10 \sim 100$ years. In the gap B region, the total $\triangle \mathrm{CFS}$ values are 50 , 50 200, 50 200 and 200 300 kPa for B1, B2, B3 and B4, respectively. With an interseismic tectonic stress loading rate of $1.5 \mathrm{kP} / \mathrm{a}$, these increased values are equivalent to the accumulation of tectonic stress for approximately 30, 30 130, 30 130 and 130 200 years.

\subsection{Conclusions}

In this study, we calculate the coseismic and postseismic Coulomb stress changes induced by 14 historical earthquakes and investigate their influences on the 2021 Maduo source area. Furthermore, we investigate the influences of all these previous events and the Maduo

Page $7 / 18$ 
event on the seismic hazard in the EKF. Combined with the consequences of tectonic loading, we examined the partitioning of stress and re-evaluated the seismic hazards of the EKF. We reached the following conclusions based on our results:

(1) The 14 historical events considered herein released the stress in the rupture zone of the Maduo earthquake with a combined approximate $\triangle \mathrm{CFS}$ range of -0.4 to $-0.2 \mathrm{MPa}$. In particular, the 1937 event had the greatest contribution of $-235 \mathrm{kPa}$ at the Maduo hypocenter. The JCF is the seismogenic fault of the 2021 Maduo event, which is almost parallel and close to the EKF (where the 1937 event occurred). Therefore, the rupture of the 1937 event delayed the occurrence of the Maduo event by inducing the typical inhibitory effect between parallel strike-slip faults on the JCF.

(2) According to the fault slip rates based on surface geodesy data, we estimated that the loading rate on the JCF is only $0.3 \mathrm{kPa} / \mathrm{a}$. However, magnetotelluric data reveal that the Maduo source area is located at the junction of high-conductivity and high-resistivity bodies in the middle and lower crust, where the tectonic stress easily concentrates locally. Therefore, we hypothesize that the actual loading rate at the depth of the seismogenic layer in the Maduo source area is much higher than the simulated value. We further suggest that although this area is in the stress shadow of historical events, long-term tectonic loading is the main control on the occurrence of this event.

(3) Our investigation reveals the enhanced stress induced by the historical and Maduo events with $\triangle$ CFS values of approximately 30 300 $\mathrm{kPa}$ and $50 \sim 300 \mathrm{kPa}$ on the XDS (gap A area) and the eastern end of the EKF (gap B area), respectively, not only on the MMS but also at the eastern end of each branch segment of the EKF. A positive $\triangle$ CFS brings a fault closer to Coulomb failure. Hence, combined with the accumulation of tectonic stress, the seismic hazard in these two regions has been promoted.

\section{Declarations}

\section{Availability of data and materials}

The datasets used during the current study are available from the corresponding author on a reasonable request.

\section{Competing interests}

Not applicable

\section{Funding}

This research was funded by the Open Foundation of the United Laboratory of Numerical Earthquake Forecasting (2020LNEF06); the Scientific Research Fund of Institute of Seismology, CEA (IS201926296); The Spark Program of Earthquake Technology of CEA (XH21020)

\section{Authors' contributions}

PD collected the information of historical earthquakes, did all the calculations, and analyzed the results; BZ provided technical support and useful advice for calculation; XQ helped analyze and interpret the results. All authors read and approved the final manuscript.

\section{Acknowledgements}

The PSGRN/PSCMP software package provided by professor Wang Rongjiang is used to calculate the stress changes. Some figures are created by Generic Mapping Tools (Wessel and Smith 1995)

\section{Authors' information}

1 Key Laboratory of Earthquake Geodesy, Institute of Seismology, China Earthquake Administration, Wuhan 430071, China

\section{References}

Chen SF, Wilson C, Deng QD, et al (1994) Active faulting and block movement associated with large earthquakes in the Min Shan and Longmen Mountains, northeastern Tibetan Plateau. J Geophys Res Solid Earth 99:

Deng Q, Cheng S, Ma J, Du P (2014) Seismic Activities and Earthquake Potential in the Tibetan Plateau. Chinese J Geophys 57:678-697. https://doi.org/10.1002/cjg2.20133

Diao F, Xiong X, Wang R, et al (2019) Slip Rate Variation Along the Kunlun Fault (Tibet): Results From New GPS Observations and a Viscoelastic Earthquake-Cycle Deformation Model. Geophys Res Lett 46:2524-2533. https://doi.org/10.1029/2019GL081940

Page 8/18 
Dong P, Liu C, Shi Y (2019) Relationship between the 2008 M_S8.0 Wenchuan Earthquake and the 2017 M_S7.0 Jiuzhaigou Earthquake. J Geod Geodyn

Eric, Kirby (2007) Slip rate gradients along the eastern Kunlun fault. Tectonics

Harris RA (1998) Introduction to Special Section: Stress Triggers, Stress Shadows, and Implications for Seismic Hazard. J Geophys Res 103:24347-24358

Hill DP, Reasenberg PA, Michael A, et al (1993) Seismicity remotely triggered by the magnitude 7.3 Landers, California, earthquake. Science (80- ) 260:1617-1623

Hou K, Lei Z, Wan F, et al (2005) Research on the 1879 Southern Wudu M8.0 Earthquake and Its Coseismic Ruptures. Earthq Res China 21:295-310. https://doi.org/10.3969/j.issn.1001-4683.2005.03.001

Huang L, Cheng $\mathrm{H}$, Zhang $\mathrm{H}$, et al (2019) Coseismic and postseismic stress evolution caused by the 2008 Wenchuan earthquake and its effects on the 2017 MS 7.0 Jiuzhaigou earthquake. Chinese J Geophys 62:1268-1281. https://doi.org/10.6038/cjg2019L0545

Jia K, Zhou S, Zhuang J, et al (2018) Did the 2008 Mw 7.9 Wenchuan Earthquake Trigger the Occurrence of the 2017 Mw 6.5 Jiuzhaigou Earthquake in Sichuan, China? J Geophys Res Solid Earth

Jia S, Lin J, Guo W, et al (2017) Investigation on diversity of crustal structures beneath the Bayan Har block. Chinese J Geophys 60:393407

Jones LM, Han W, Hauksson E, et al (1984) Focal mechanisms and aftershock locations of the Songpan earthquakes of August 1976 in Sichuan, China. J Geophys Res Solid Earth 89:

Kato N, Lei X (2001) Interaction of parallel strike-slip faults and a characteristic distance in the spatial distribution of active faults. Geophys J Int 144:157-164. https://doi.org/10.1046/j.0956-540X.2000.01310.x

King GCP, Stein RS, Jian Lin (1994) Static stress changes and the triggering of earthquakes. Bull - Seismol Soc Am 84:935-953. https://doi.org/10.1016/0148-9062(95)94484-2

Lasserre C, Peltzer G, Crampé F, et al (2005) Coseismic deformation of the $2001 \mathrm{Mw}=7.8$ Kokoxili earthquake in Tibet, measured by synthetic aperture radar interferometry. J Geophys Res Solid Earth 110:

Li CX, Xu XW, Wen XZ, et al (2011a) Rupture segmentation and slip partitioning of the mid-eastern part of the Kunlun Fault, north Tibetan Plateau. Sci China Earth Sci 54:1730-1745. https://doi.org/10.1007/s11430-011-4239-5

Li J, Zhang J, Cai Y (2017) Investigation of Historical Earthquakes,Paleo-earthquakes and Seismic Gap in the Eastern Kunlun Fault Zone. Earthquake

Li Y, Huang L, Ding R, et al (2021) Coulomb stress changes associated with the M7.3 Maduo earthquake and implications for seismic hazards. Nat Hazards Res 1:95-101. https://doi.org/10.1016/j.nhres.2021.06.003

Li Y, Shan X, Qu C (2019) Geodetic constraints on the crustal deformation along the Kunlun fault and its tectonic implications. Remote Sens 11:1-16. https://doi.org/10.3390/rs11151775

Li Z, Elliott JR, Feng W, et al (2011b) The 2010 MW 6.8 Yushu (Qinghai, China) earthquake: Constraints provided by InSAR and body wave seismology. J Geophys Res 116:

Lin A, Guo J (2008) Nonuniform Slip Rate and Millennial Recurrence Interval of Large Earthquakes along the Eastern Segment of the Kunlun Fault, Northern Tibet. Bull Seismol Soc Am 98:2866-2878

Liu C, Dong P, Zhu B, Shi Y (2018) Stress Shadow on the Southwest Portion of the Longmen Shan Fault Impacted the 2008 Wenchuan Earthquake Rupture. J Geophys Res Solid Earth 123:9963-9981. https://doi.org/10.1029/2018JB015633

Liu C, Zhu B, Shi Y (2020) Do the Two Seismic Gaps in the Southwestern Section of the Longmen Shan Fault Present the Same Seismic Hazard? J Geophys Res Solid Earth 125:. https://doi.org/10.1029/2019JB018160

Page 9/18 
Liu G, Xiong W, Wang Q, et al (2019) Source Characteristics of the 2017 Ms 7.0 Jiuzhaigou, China, Earthquake and Implications for Recent Seismicity in Eastern Tibet. J Geophys Res Solid Earth

Liu L, Li Y, Zhu L, Ji L (2021) Influence of the 1947 Dari M7.7 earthquake on stress evolution along the boundary fault of the Bayan Har block: insights from numerical simulation. Acta Geophys Sin 64:2221-2231. https://doi.org/10.6038/cjg2021P0194

Meissner R, Tilmann F, Haines S (2004) About the lithospheric structure of central Tibet, based on seismic data from the INDEPTH III profile. Tectonophysics 380:1-25. https://doi.org/https://doi.org/10.1016/j.tecto.2003.11.007

Molnar P, Qidong D (1984) Faulting associated with large earthquakes and the average rate of deformation in central and eastern Asia. J Geophys Res Solid Earth 89:6203-6227

Moyer PA, Boettcher MS, Mcguire JJ, Collins JA (2018) Spatial and Temporal Variations in Earthquake Stress Drop on Gofar Transform Fault, East Pacific Rise: Implications for Fault Strength. J Geophys Res Solid Earth 123:

Parsons T, Ji C, Kirby E (2008) Stress changes from the 2008 Wenchuan earthquake and increased hazard in the Sichuan basin. Nature 454:509-510

Qu WL, Zhang B, Huang LY, et al (2016) Comparisons of global coseismic displacements from several fault slip models for the 2004 Sumatra earthquake. Chinese J Geophys

Ren J, Xu X, Zhang S, et al (2017) Surface rupture of the 1933 M 7.5 Diexi earthquake in eastern Tibet: implications for seismogenic tectonics. Geophys J Int

Shan B, Xiong X, Wang R, et al (2015) Stress evolution and seismic hazard on the Maqin-Maqu segment of East Kunlun Fault zone from co-, post-and interseismic stress changes. Geophys J Int 200:244-253. https://doi.org/10.1093/gji/ggu395

Shen Z, Wan Y, Gan W, et al (2003) Viscoelastic Triggering Between Large Earthquakes along the East Kunlun Fault System. Chinese J Geophys 46:1125-1138. https://doi.org/10.1002/cjg2.432

Shi Y, Yin D, Ren T, et al (2021) The variation of coseismic static stress deviation consistent with theoretical prediction was observed for the first time -Observation of borehole strain of the Yuanping ML4.7 earthquake in Shanxi on April 7, 2016. Acta Geophys Sin 64:19371948. https://doi.org/10.6038/cjg202100398

Shi, Yaolin, Dong, et al (2017) Stress change from the 2015 Mw 7.8 Gorkha earthquake and increased hazard in the southern Tibetan Plateau. Phys Earth Planet Inter A J Devoted to Obs Experimerntal Stud Chem Phys Planet Inter Their Theor Interpret 267:1-8

Silver P (2008) S-wave crustal and upper mantle's velocity structure in the eastern Tibetan Plateau--Deep environment of lower crustal flow. Sci China(SeriesDEarth Sci 02:263-274. https://doi.org/CNKI:SUN:JDXG.0.2008-02-012.

Stein RS (1999) The role of stress transfer in earthquake occurrence. Nature 402:605-609. https://doi.org/10.1038/45144

Stein RS, King GCP, Lin J (1994) Stress triggering of the 1994 M = 6.7 Northridge, California, Earthquake by its predecessors. Science (80- ) 265:1432-1435. https://doi.org/10.1126/science.265.5177.1432

Stein RS, Lisowski M (1983) The 1979 Homestead Valley Earthquake Sequence, California: Control of aftershocks and postseismic deformation. J Geophys Res Solid Earth 88:

Taira, Taka'aki, Silver, et al (2009) Remote triggering of fault-strength changes on the San Andreas fault at Parkfield. Nature

Toda S, Lin J, Meghraoui M, Stein RS (2008) 12 May 2008 M = 7.9 Wenchuan, China, earthquake calculated to increase failure stress and seismicity rate on three major fault systems. Geophys Res Lett 35:

Van Der Woerd J, Ryerson FJ, Tapponnier P, et al (2000) Uniform slip-rate along the Kunlun Fault: Implications for seismic behaviour and large-scale tectonics. Geophys Res Lett 27:2353-2356. https://doi.org/10.1029/1999GL011292

Wan Y, Shen Z, Zeng Y, Sheng S (2007) Evolution of cumulative Coulomb failure stress in northeastern Qinghai-Xizang (Tibetan) Plateau and its effect on large earthquake occurrence. Acta Seismol Sin 29:15-129

Page 10/18 
Wang K, Shen Z (2011) Location and focal mechanism of the 1933 Diexi earthquake and its associated regional tectonics. Acta Seismol Sin 33:557-567. https://doi.org/10.3969/j.issn.0253-3782.2011.05.001

Wang Q, Qiao X, Lan Q, et al (2011) Rupture of deep faults in the 2008 Wenchuan earthquake and uplift of the Longmen Shan. Nat Geosci 4:634-640. https://doi.org/10.1038/ngeo1210

Wang R, Lorenzo-Martín F, Roth F (2006) PSGRN/PSCMP-a new code for calculating co- and post-seismic deformation, geoid and gravity changes based on the viscoelastic-gravitational dislocation theory. Comput Geosci 32:527-541

Wang W, Fang L, Wu J, et al (2021) Aftershock sequence relocation of the 2021 MS7.4 Maduo Earthquake, Qinghai, China. Sci China Earth Sci

Wells BDL, Coppersmith KJ (1994) New empirical relationships among magnitude, rupture length, rupture width, rupture area, and surface displacement. Bull.seism.soc.am 84:974-1002

Wen X (2018) The 2008 Wenchuan, 2013 Lushan and 2017 Jiuzhaigou earthquakes, Sichuan, in the last more than one thousand years of rupture history of the eastern margin of the Bayan Har block. Acta Seismol Sin 40:255-267. https://doi.org/10.11939/jass.20170211

Xiao J, He J (2015) 3D Finite-Element Modeling of Earthquake Interaction and Stress Accumulation on Main Active Faults around the Northeastern Tibetan Plateau Edge in the Past 100 Years. Bull Seismol Soc Am 2724-2735

Xiong X, Shan B, Yong Z, Wang R (2010) Stress transfer and its implication for earthquake hazard on the Kunlun Fault, Tibet.

Tectonophysics 482:216-225

Xu X, Chen W, Ma W, et al (2002) Surface Rupture of the Kunlunshan Earthquake (M s 8.1), Northern Tibetan Plateau, China. Seismol Res Lett 73:884-892

Xu XW, Cheng J, Xu C, et al (2014) Discussion on block kinematic model and future themed areas for earthquake occurrence in the Tibetan Plateau: inspiration from the Ludian and Jinggu earthquakes. Seismol Geol 36:1116-1134

Yue H, Zhang Z, Chen YJ (2008) Interaction between adjacent left-lateral strike-slip faults and thrust faults: The 1976 Songpan earthquake sequence. Chinese Sci Bull 53:2520-2526. https://doi.org/10.1007/s11434-008-0210-z

Zhu L, Ji L, Jiang F (2020) Variations in Locking Along the East Kunlun Fault, Tibetan Plateau, China, Using GPS and Leveling Data. Pure Appl Geophys 177:

Zhu L, Ji L, Liu C (2021a) Interseismic slip rate and locking along the Maqin-Maqu Segment of the East Kunlun Fault, Northern Tibetan Plateau, based on Sentinel-1 images. J Asian Earth Sci 211:104703. https://doi.org/10.1016/j.jseaes.2021.104703

Zhu S, Miao M (2016) A Study on Earthquake Triggering: Solution to the Paradox of Coulomb Stress Increase with Frictional Coefficients. Chinese J Geophys 59:15-19. https://doi.org/10.1002/cjg2.20209

Zhu Y, Diao F, Yuchao FU, et al (2021b) Slip rate of the seismogenic fault of the 2021 Maduo earthquake in western China inferred from GPS observations. Sci China Earth Sci 64:8

Pan J W, Bai M K, Li C, et al (2021) Coseismic surface rupture and seismogenic structure of the 2021-05-22 Maduo (Qinghai )MS 7. 4 earthquake. Acta Geologica Sinica 95(6):1655-1670. Doi: 10.3969/j.issn.0001-5717.2021.06.001

\section{Figures}




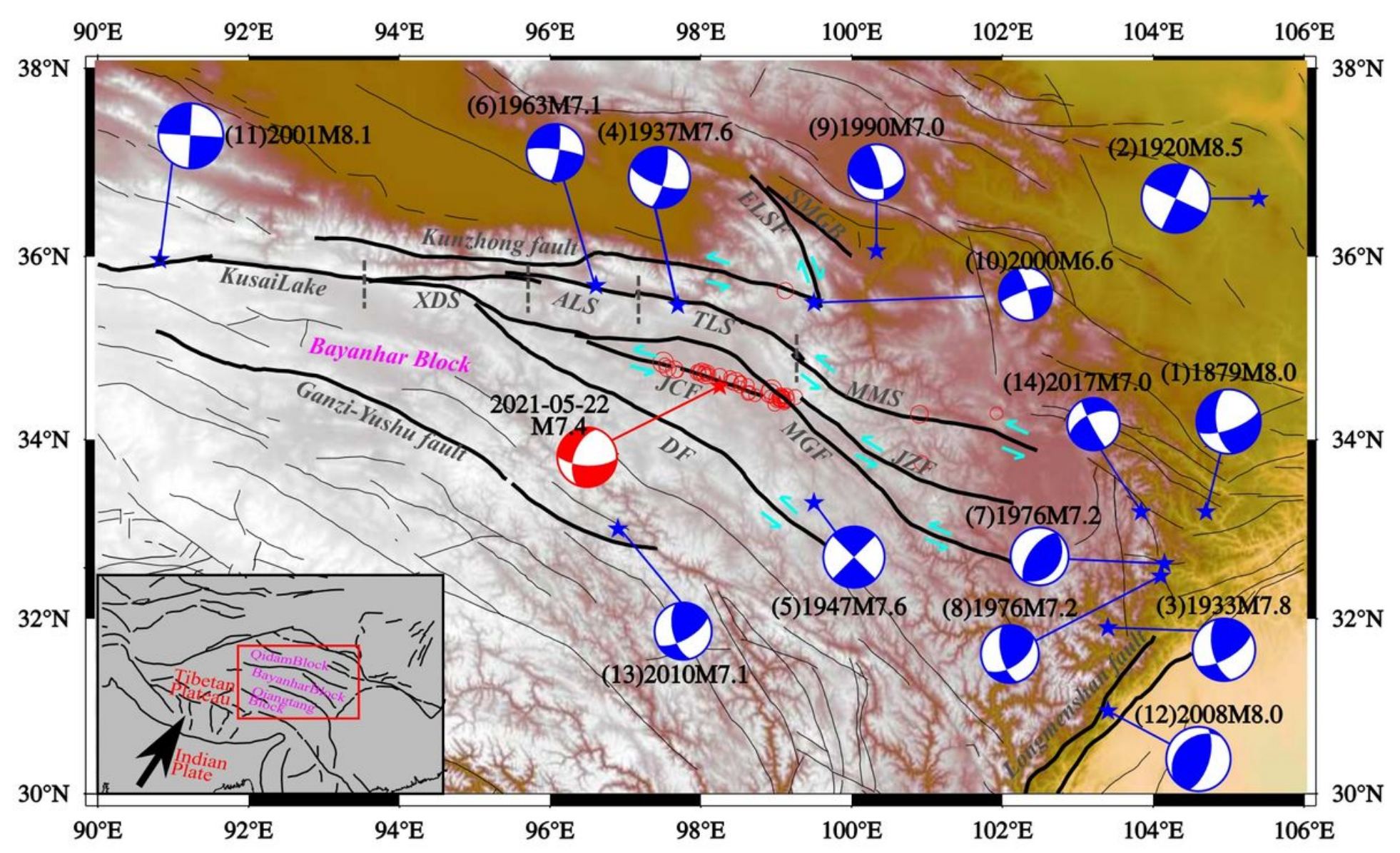

Figure 1

Tectonic setting, wherein the blue stars show epicenter of the $M>6.5$ earthquakes spatial distribution on and around EFK; the red star shows the 2021 Maduo earthquake epicenter; the beach balls define the earthquake focal mechanism; the black solid lines define the faults. The detailed earthquake parameters (focal depths, focal mechanisms) are summarized in Table 1. The lower left inset presents the location of target area in the larger geological setting. 


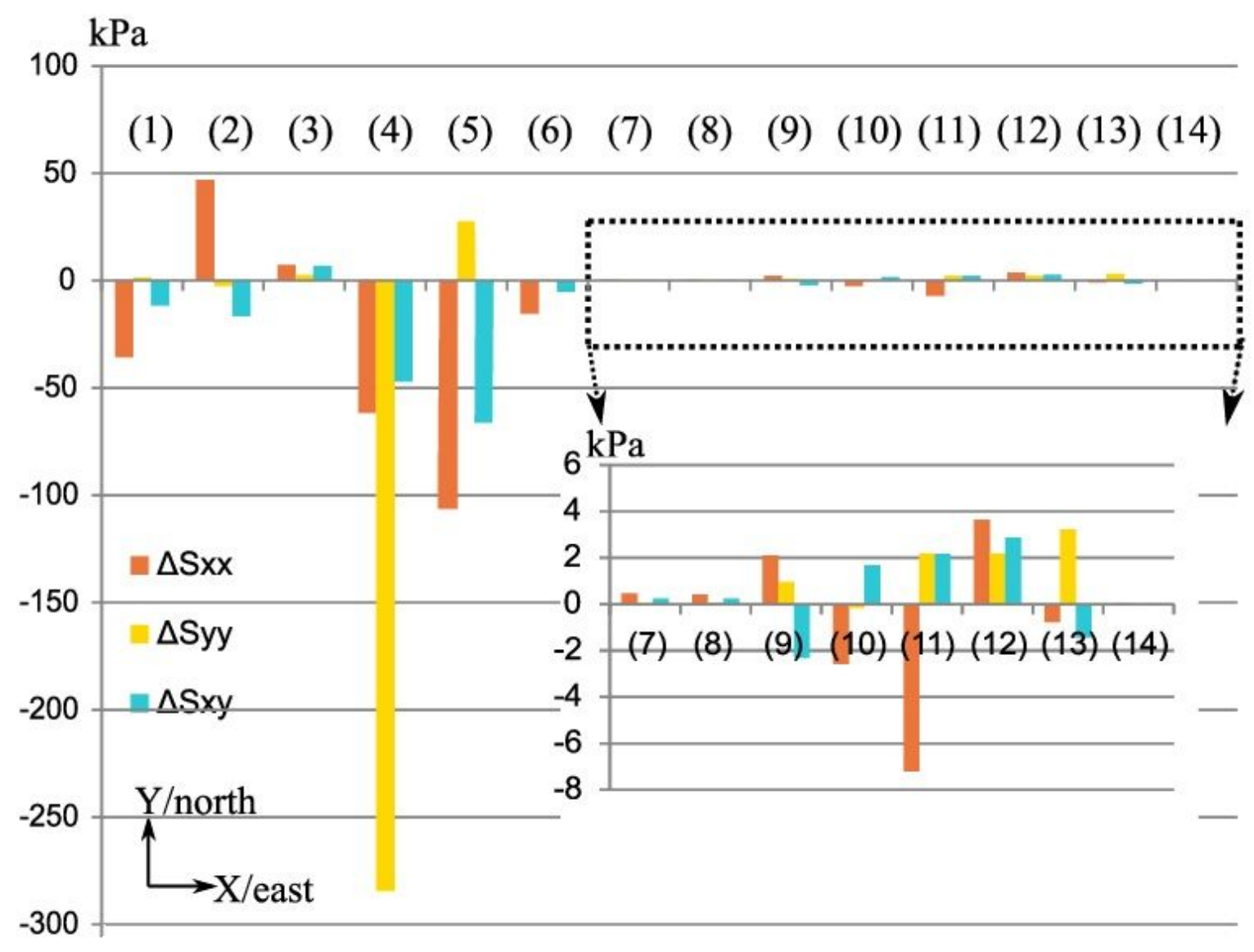

Figure 2

The combined stress change in three components caused by 14 historical earthquakes at the hypocenter of 2021 earthquake (depth=10km). Number (1) (14) represents the 14 events, respectively, same as Table 1

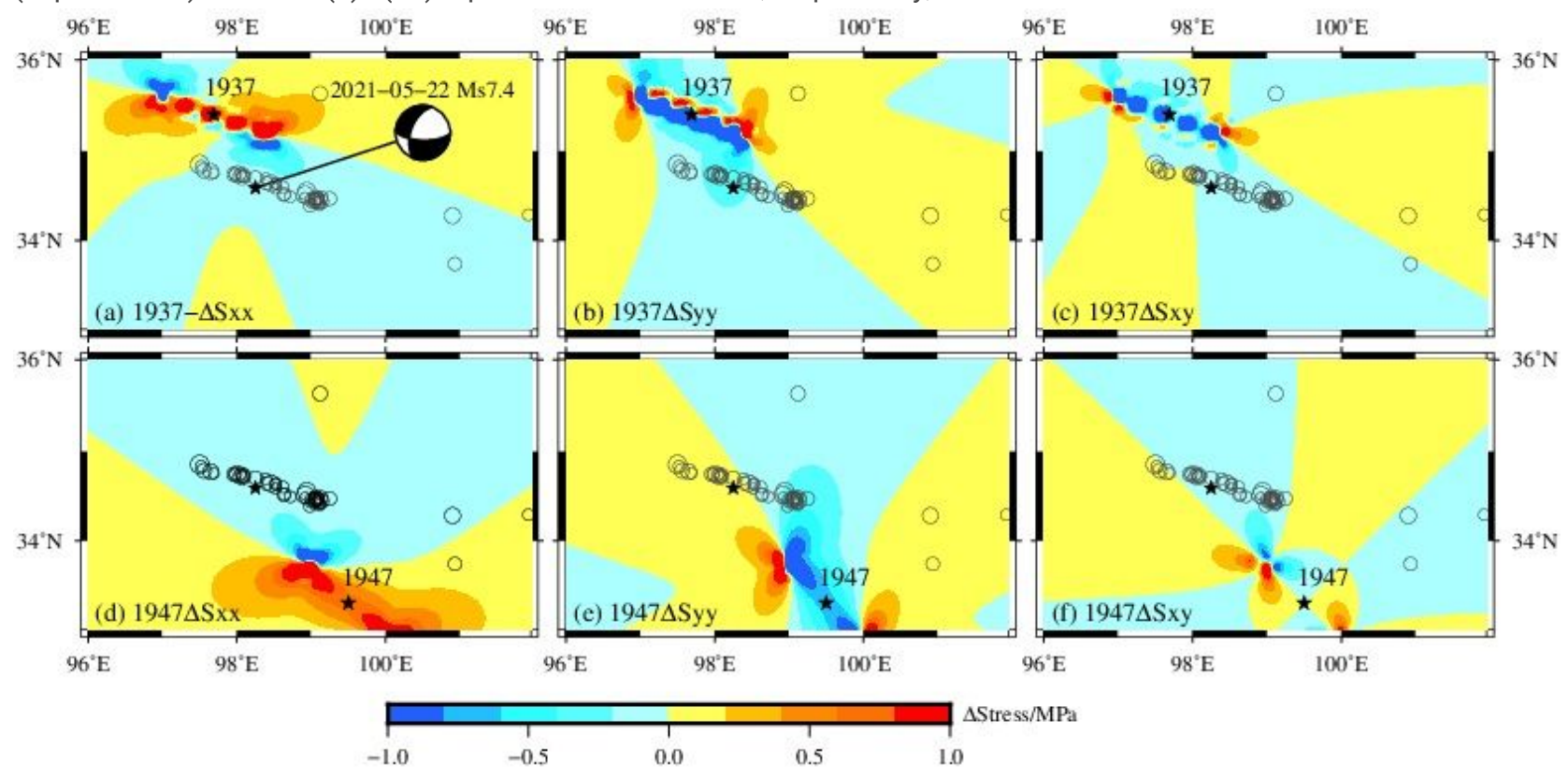

Figure 3

Stress changes caused by the 1937 and 1947 earthquake. (a) (c) are the $\Delta$ Sxx, $\Delta$ Syy, $\Delta$ Sxy caused by 1937 earthquake, respectively; (d) (f) are the $\Delta S x x, \Delta S y y, \Delta S x y$ caused by 1947 earthquake, respectively; Black beach ball show the Maduo earthquake, black circles represent the aftershock of Maduo event, black stars define the epicenter of the earthquakes. 


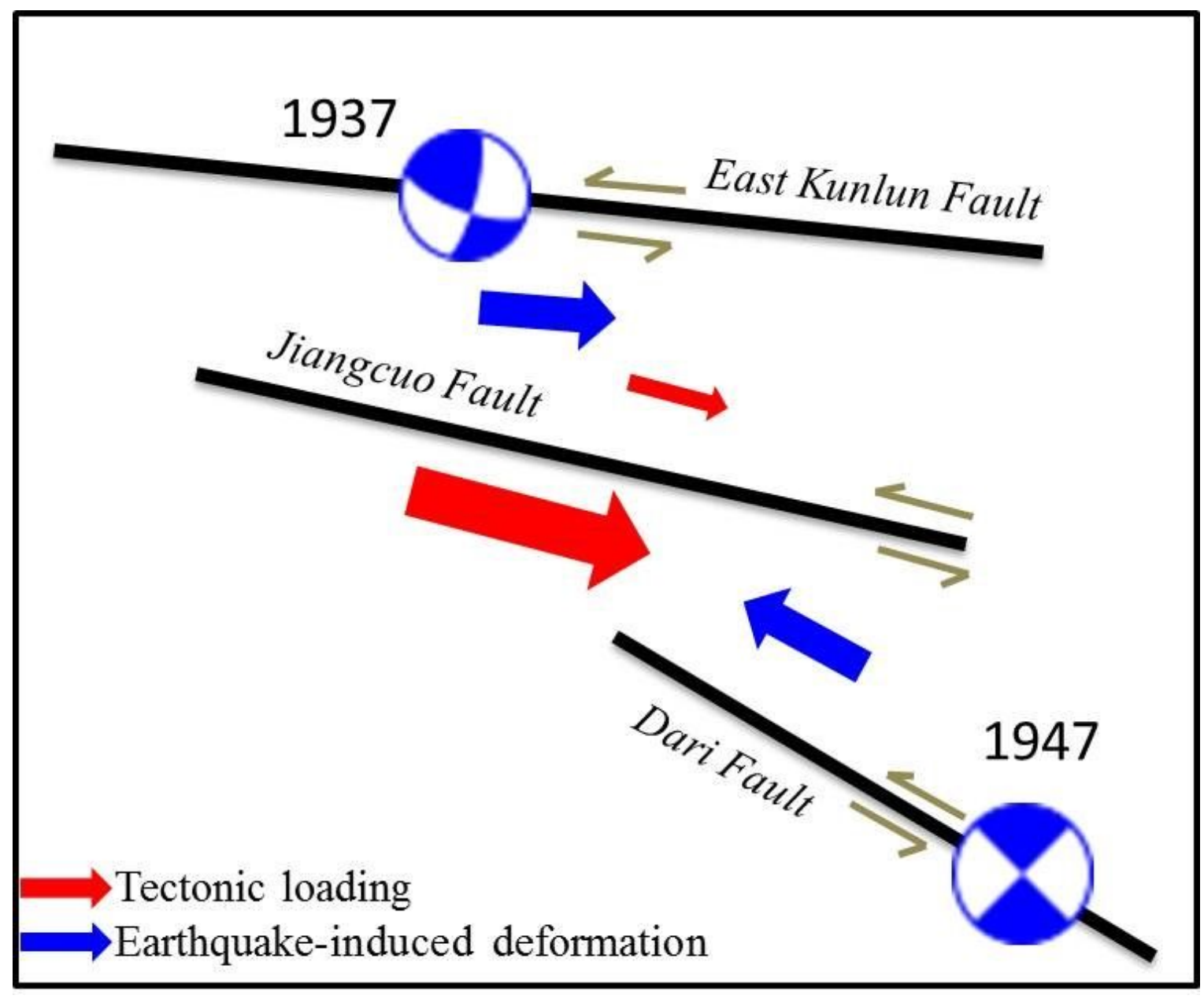

Figure 4

The sketch map of the impact of two earthquakes and the tectonic activity 


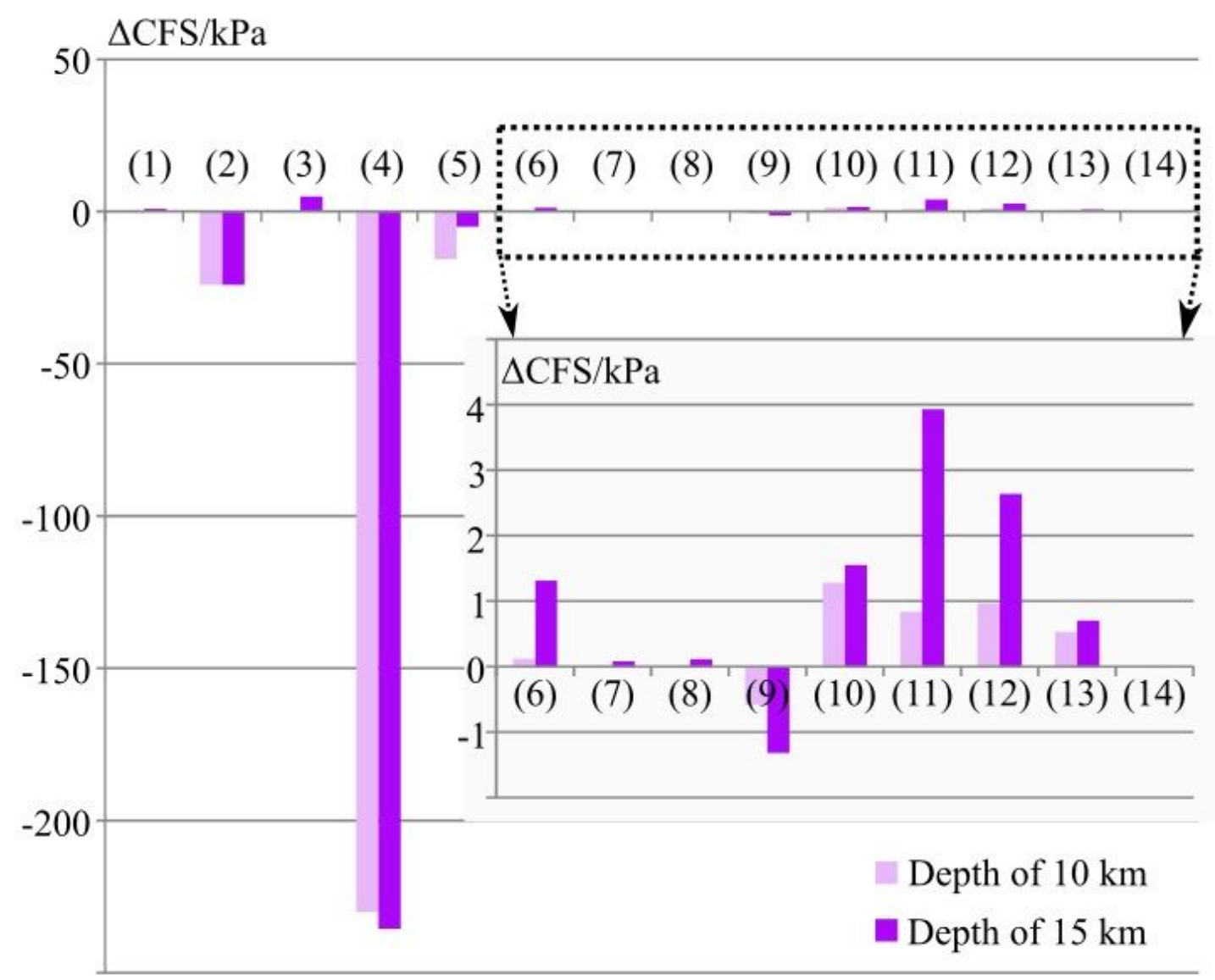

Figure 5

The coseismic and postseismic $\triangle$ CFS at the epicenter of 2021 Maduo earthquake induced by historical earthquakes, at different depth $10 \mathrm{~km}$ and $15 \mathrm{~km}$.

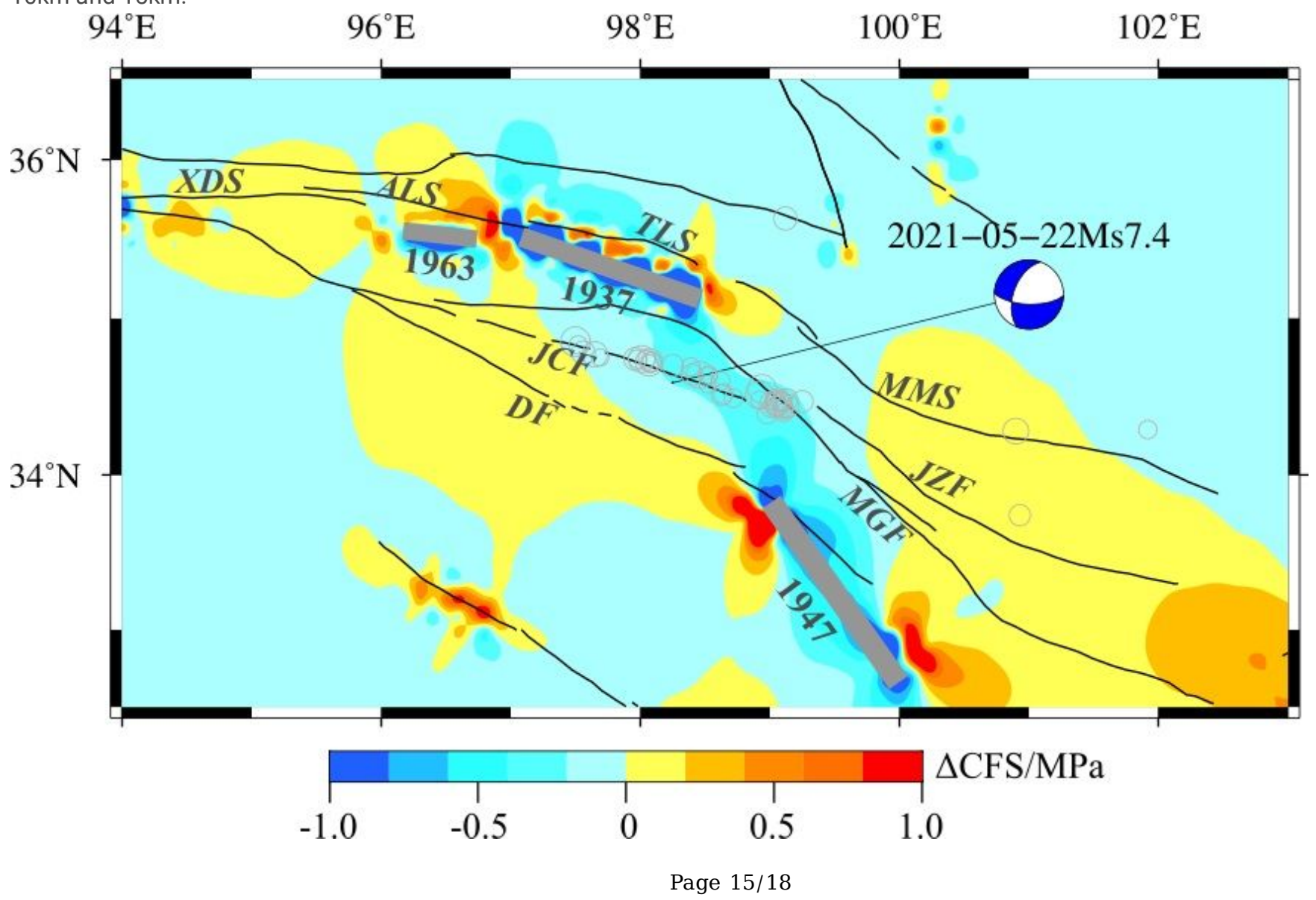


Figure 6

The combined $\triangle$ CFS induced by 14 earthquakes

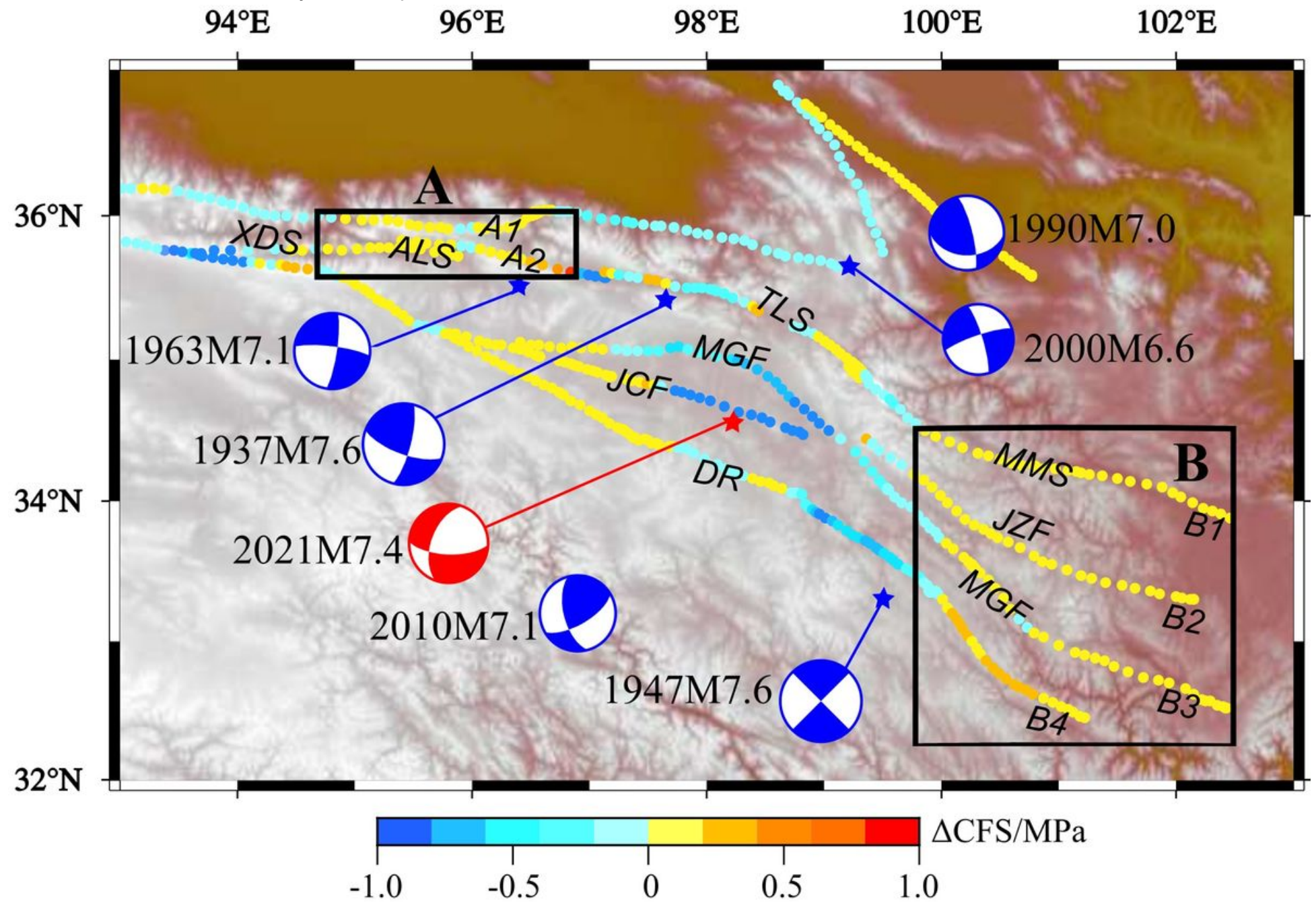

Figure 7

The combined $\triangle$ CFS on major faults caused by 14 historical events and 2021 event $\triangle \mathrm{CFS} / \mathrm{kPa}$
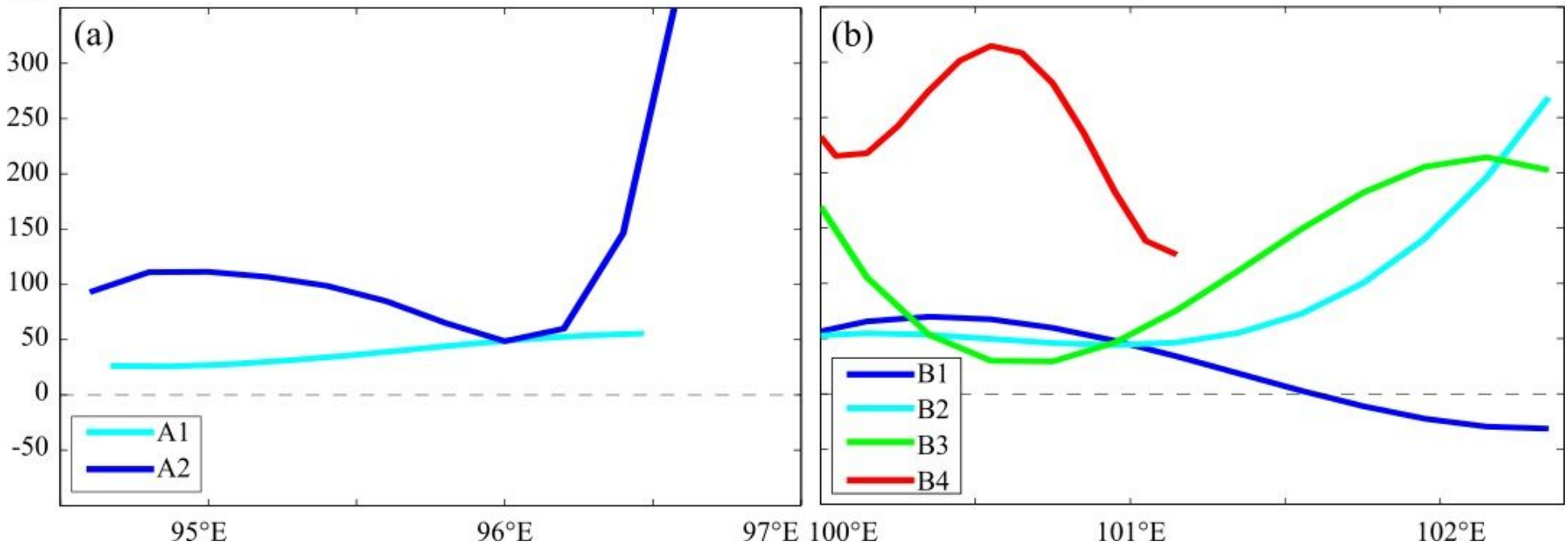

Figure 8

The combined $\triangle$ CFS on gap $A$ and gap $B$ area. 

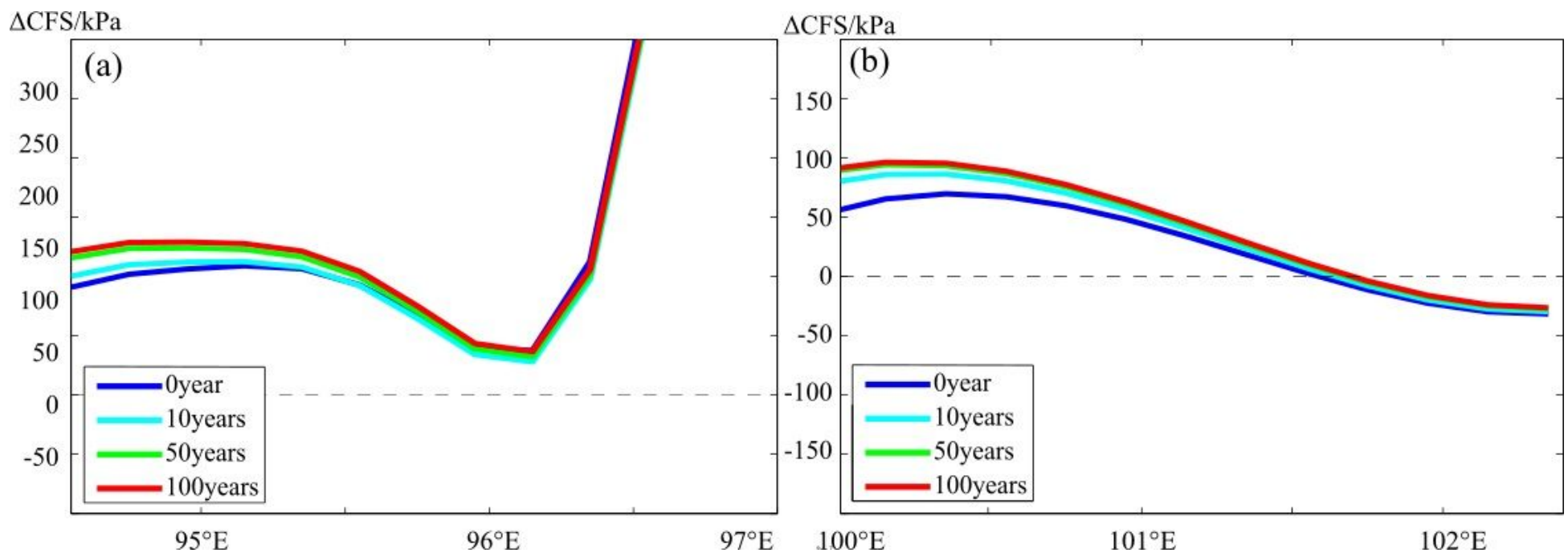

Figure 9

$\triangle \mathrm{CFS}$ on $\mathrm{A} 1$ and $\mathrm{B} 1$ at time intervals of $0,10,50$ and 100 years after 2021

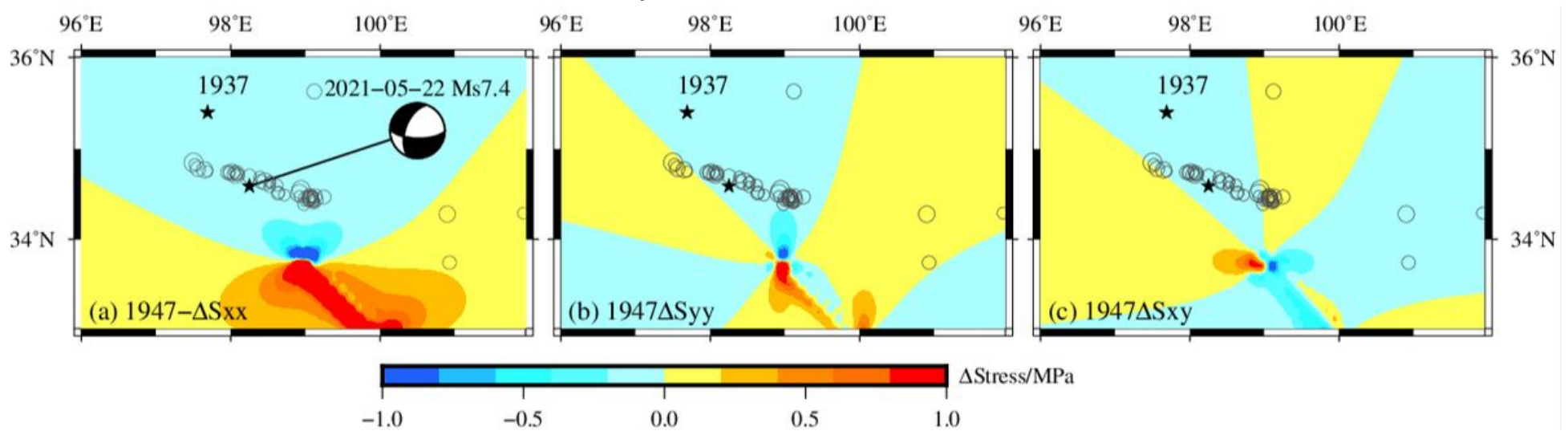

Figure 10

Stress change induced by 1947 event with the other focal mechanism 


\section{$\triangle \mathrm{CFS} / \mathrm{kPa}$}
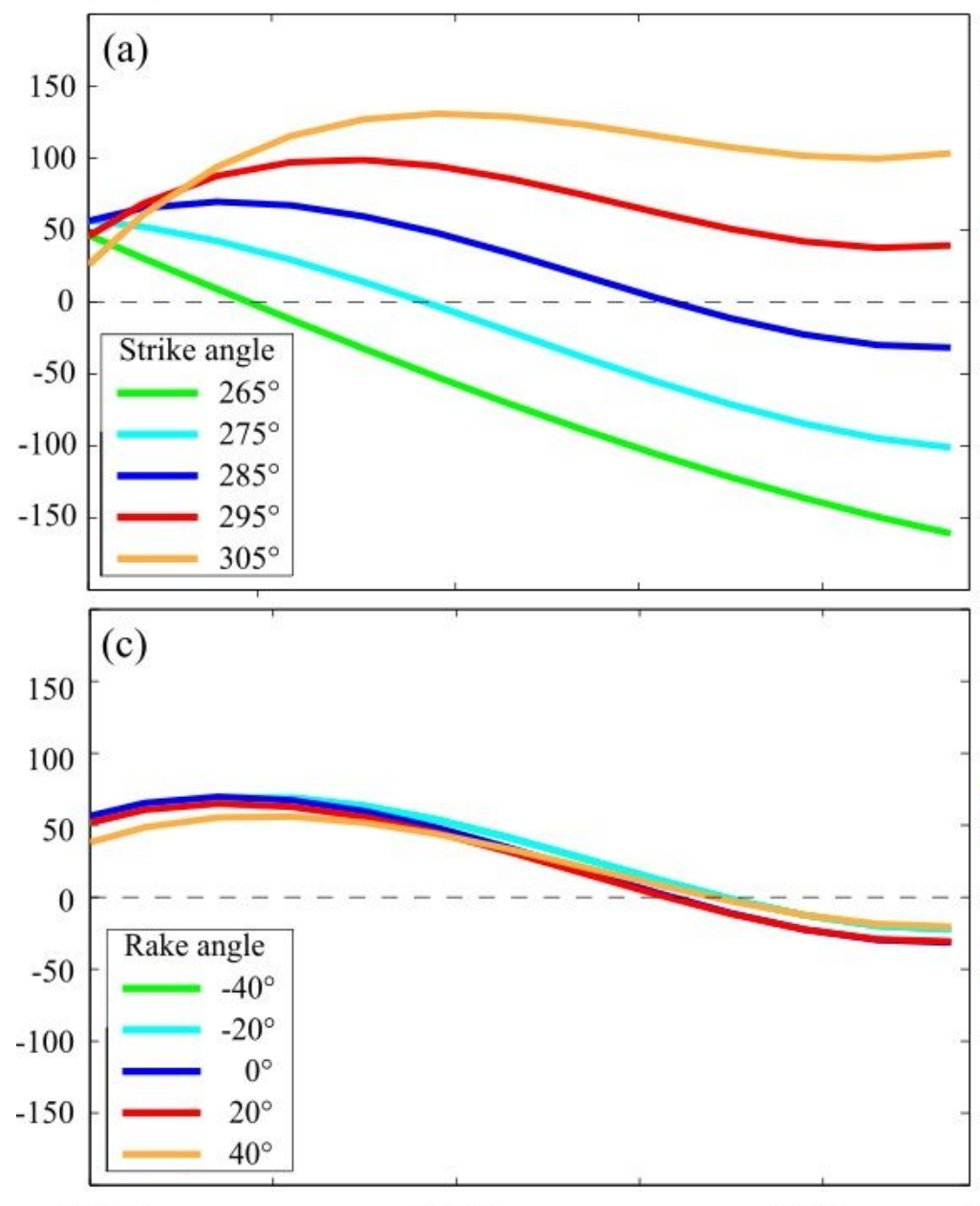

$100^{\circ} \mathrm{E}$ (b)
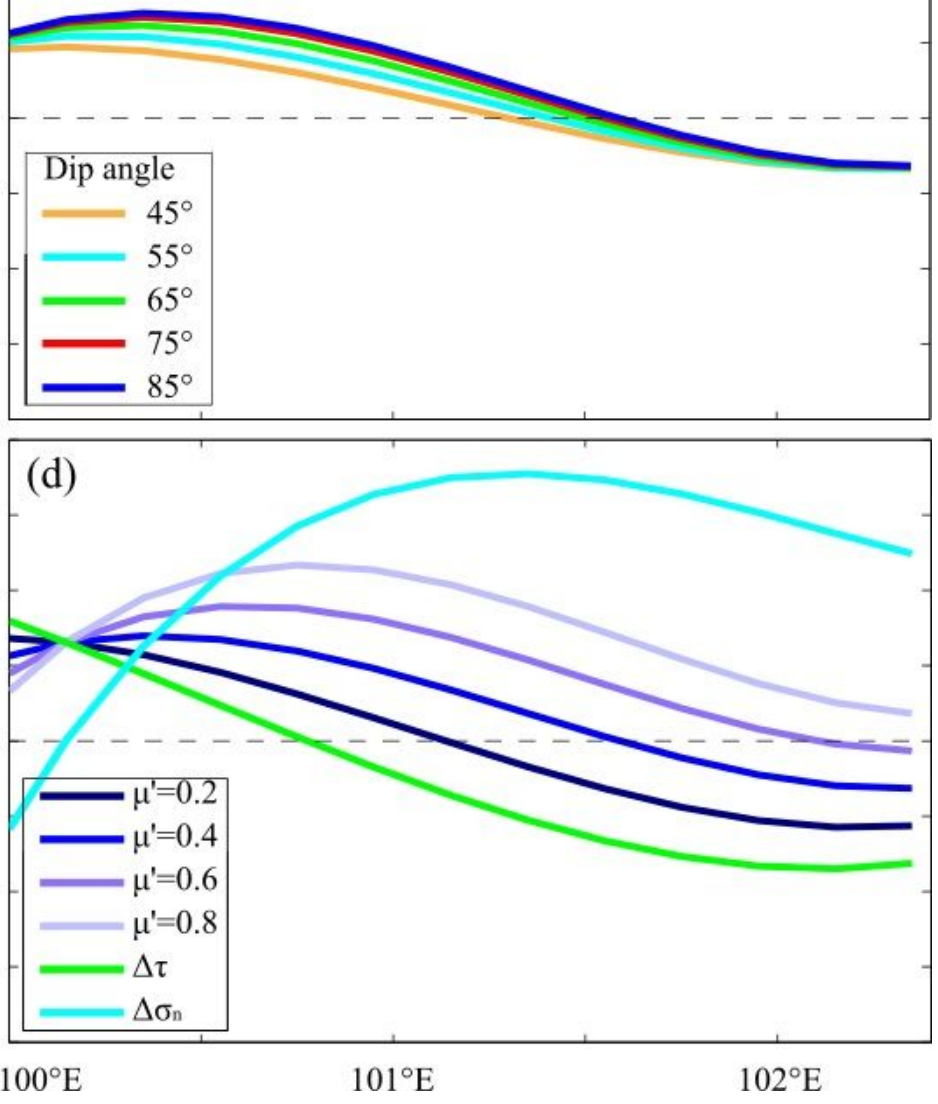

Figure 11

$\triangle \mathrm{CFS}$ in the MMS(B1) produced by 14 historical and 2021 Maduo events for various parameters. 